\title{
Assessing the impact of aquaculture farms using remote sensing: an empirical neural network algorithm for Ildırı Bay, Turkey
}

\author{
Fethi Bengil* ${ }^{*}$ K. Can Bizsel \\ Dokuz Eylül University, Institute of Marine Sciences and Technology, Bakü Bulv. No. 100, 35340 Inciraltı, Izmir, Turkey
}

\begin{abstract}
The potential impact of aquaculture on Ildırı Bay, Turkey, was assessed using remote sensing data collected over 37 d between September 2009 and February 2011. The dataset was improved by applying a local empirical neural network (NN) algorithm. Impact was evaluated in terms of total suspended matter (TSM) and Secchi disk depth (SDD) as effective variables showing changes in underwater light fields in each defined subarea. Subareas were farm sites with their peripheries (impact zones) and the whole study area for 2 different regions within the bay. Real-time datasets of TSM and SDD were obtained for 7 different days within the same period. To create an NN algorithm, the full swath of geo-located products (with $300 \mathrm{~m}$ resolution) from the MERIS sensor aboard ENVISAT was used along with in situ data. The NN algorithm showed good performance, with an accuracy of $97.46 \%$ for TSM and $99.58 \%$ for SDD. No significant $\left(F_{\mathrm{s}}>0.05\right)$ impact on the environment was observed; however, the time series analyses of similarities and anomalies showed that the impact zones have different temporal characteristics compared to the whole bay and vice versa. The highest particle concentrations and lowest light penetration occurred in the spring and summer. Water circulation patterns were identified as the major force determining the distribution and hence the source of particles and were also applied to reflect the particle loads introduced by feeding activity performed in aquaculture facilities. The influence of dissolved organic carbon to TSM and SDD indicates that the contribution of colored dissolved organic matter is another important variable for effective monitoring of aquaculture activity in the bay.
\end{abstract}

KEY WORDS: Ocean color · MERIS - Artificial neural network $\cdot$ Spatial and temporal variability

\section{INTRODUCTION}

As a result of the fragile balance between terrestrial and marine ecosystems, the coastal zone is the world's largest ecotone, which refers to a place where rich biodiversity and ecological resources are available. This richness is highly attractive to human beings. Today, more than half of the global human population lives in coastal zones, resulting in an enormous number of socio-economical and recreational activities which create profound conflicts with the fragile balance of these ecosystems. In many countries, people live near the coast not by choice but

\footnotetext{
${ }^{*}$ Corresponding author: fethi.bengil@deu.edu.tr
}

by necessity, as coasts supply food, products that can be imported or exported, a means for shipping, and a mode of travel (IOCCG 2008).

Marine ecosystems cover a major percentage of Earth's surface and are driven by the interactions between organisms and their external conditions. The balance of these systems can collapse due to anthropogenic effects. Growing human populations and increasing food demand lead people to search for alternative food supplies. As highlighted by the Pure Salmon Group (2006), by replacing wild fisheries with farmed fish, aquaculture has the potential to reduce the pressure on marine systems and limit

() The authors 2014. Open Access under Creative Commons by Attribution Licence. Use, distribution and reproduction are unrestricted. Authors and original publication must be credited. 
the overall human impact on marine environments. On the other hand, conflicts of aquaculture with other socio-economical sectors/activities have increased, in parallel with the increasing number of aquaculture facilities. This fact has raised arguments on aquaculture activities and discussions on new approaches to management, including regulatory measures and monitoring of these activities.

Studies have demonstrated the impact of fish farming activities in the water column. Using a comprehensive dataset, Sarà (2007) showed the impact of aquaculture on physical and chemical properties of the water column. Remotely sensed data have been used for nearshore aquaculture site selection for more than 20 yr (Kapetsky et al. 1987, Kapetsky \& Aguilar-Manjarrez 2007), as survey tools for field work (Edwards 2000) and as input data for GIS analysis for suitability maps (Giap et al. 2003, Buitrago et al. 2005, IOCCG 2009). IOCCG (2009) indicated the advantages of using remote sensing in aquaculture, and approaches include providing information on where to base fish and shellfish farms by taking into account factors such as water quality, transport of nutrients, and sea surface temperature. GIS, with its spatial analysis capability, can also be used in complex aquaculture management issues, because GIS applications can manipulate, analyze, and attribute spatial data from all sources, and it can also be an effective tool when used together with remote sensing and mapping in the management and monitoring of aquaculture activities (Kapetsky \& AguilarManjarrez 2007).

Coastal waters are optically complex because of the presence of suspended sediments, phytoplankton cells, and dissolved organic matter (Bukata et al. 1991, Keiner \& Yan 1998). The neural network (NN) approach involves inverting the relationship between reflectance in different spectral bands and the concentrations of multiple types of water constituents. For this purpose, the NN is used as a multiple non-linear regression technique, and is thus related to the simpler case of linear regression (IOCCG 2000). The studies that are mentioned in IOCCG (2000) work by simulating a large number of interconnected simple processing units that resemble abstract versions of neurons. Multi-layer perceptions of an NN are the so-called feed-forward network, and are typically used in function approximation applications. All information moves in 1 direction during operation, from the input layer to the output layer. The first layer distributes the input parameters to the second layer. The second layer consists of a varying number of neurons, where each input parameter is multiplied by the weight parameter of its connection, and all the inputs to the neuron are summed and passed through the nonlinear sigmoid function. The third layer receives the output of the second layer, in which it is processed through the neurons again (Keiner 1999, Zhang et al. 2002).

As a developing country with a considerable coastal area, Turkey has increased its investments in aquaculture in the last decades in order to meet the country's demand for fish. Production in marine farms increased from $26868 \mathrm{t}$ in 2002 to $86629 \mathrm{t}$ in 2012 (BSGM 2013). Debates on the adverse environmental effects of aquaculture arose in the country during those years, and conflicts with other sectors, especially tourism, became a difficult management problem. By 2007, legal arrangements had been made, resulting in a decrease in marine farm facilities in Turkey. These changes in the sector have raised the need for objective evaluation methods for the impact of aquaculture on the marine environment, determination of the conflicts with other uses, and site selection. Remote sensing techniques, with their capability for data derivation, along with GIS and its enhanced spatial analysis, can help to meet these needs.

This study aims to make effective use of remote sensing via detecting total suspended matter (TSM) and Secchi disk depth (SDD) to evaluate the possible adverse effects of aquaculture on the marine ecosystem. The aquaculture activity in this study refers specifically to marine aquaculture. Ildırı Bay, an officially allocated area for intense aquaculture activity, was chosen as the study area. The effects were evaluated in terms of TSM and SDD. The analysis focused on the derivation of data from satellite imagery using an artificial NN approach. A second objective was to construct a time series of remotely sensed data to evaluate the temporal changes, which can be further developed for effective monitoring in dynamic marine ecosystems.

\section{MATERIALS AND METHODS}

\section{Study area}

The Bay of Ildır is located on the central eastern coast of the Aegean Sea in Turkey and is surrounded by the Çeşme and Karaburun Peninsulas. The opening of the bay includes some islands that separate the bay into 2 parts, connecting it with the Chios Strait (Fig. 1).

The bay is characterized by a high density of fish farming sites (Fig. 1). As highlighted by Demirel 


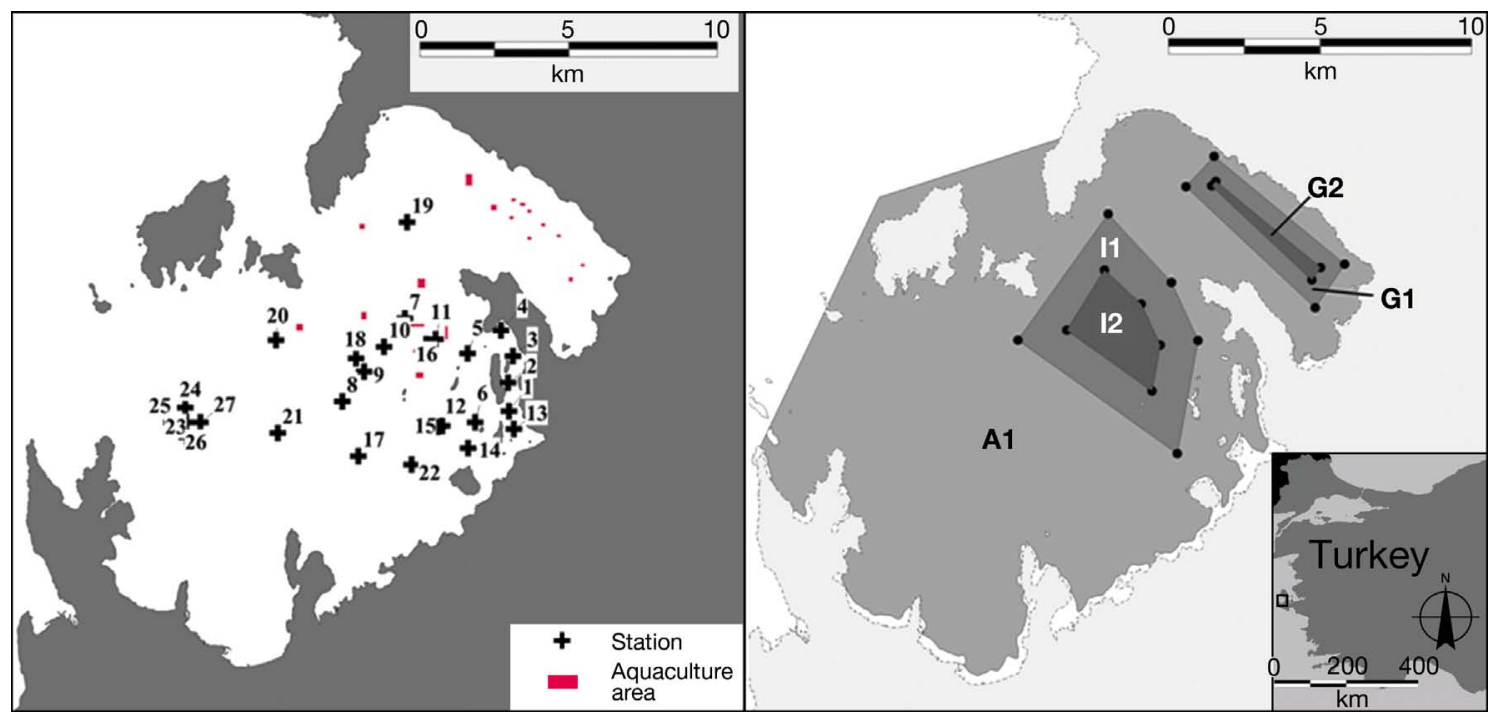

Fig. 1. Distribution of (a) sampling stations and (b) aquaculture impact zones. Inset shows the study area (rectangle). Impact zones were defined and classified for 2 cases and 2 regional groups: Region I (central Ildırn Bay) and Region G (central Gerence region of the bay). In the first case (I1 and G1), borders of the impact zones were $300 \mathrm{~m}$ away from the margins of the cage platforms. In the second case, the impact zones were narrowed to a distance of $1.2 \mathrm{~km}$ (I2) and $0.6 \mathrm{~km}$ (G2) inside the borders of both zones of the first case. Zone A1 in panel b represents the entire bay

(2010), data from the Provincial Agriculture Directorate shows that $15690 \mathrm{t}$ of aquaculture fish (sea bream and sea bass) are produced by 20 facilities in Ildırı Bay each year. Tuna fish ranching facilities are also present in the bay. Another important activity in the bay is tourism. Çeşme, one of the most popular tourism destinations in Turkey, is located on the southern side of Ildırn Bay. The tourism profile of Çeşme is predominantly sea/sun/sand, and this implies that tourism activity in the area is another important source of impact to the marine ecosystem (Akyurt 2008, Demirel 2010).

\section{In situ measurements}

The dataset used in this study extends from February 2010 to February 2011. In situ datasets used in this study were collected under the research project TUBITAK-CAYDAG 107 Y225 that aimed to represent the biogeochemical characteristics of Ildır Bay.

Water samples from each station were taken from the sub-surface layer of the sea $(0-0.5 \mathrm{~m})$. Analyses of TSM $\left(\mathrm{mg} \mathrm{l}^{-1}\right)$ were carried out by filtering samples on Whatman GF/F glass microfiber filters $(47 \mathrm{~mm}$ diameter, 0.45 micron pore size). Filters were dried at a fixed temperature $\left(105^{\circ} \mathrm{C}\right)$ to a constant weight before and after filtration. The increase in weight of each filter corresponds to the TSM concentration in the sea water sample (Sipelgas et al. 2009).

\section{Satellite imagery: MERIS}

MERIS FRS (Full Resolution Level 1) data were obtained from the European Space Agency (ESA $;$ https: //oa-es.eo.esa.int/ra/mer_frs_l1/index.php, access permitted on request) by the PI 6611 project between September 2009 and February 2011, excluding November and December 2010 because of technical problems with the ESA data system. A 16 mo sampling period between September 2009 and February 2011 was chosen based on the quality of images with adequate areal coverage and their match with in situ measurements for the empirical NN algorithm. In total, there were 37 sampling days, which included images selected for calibration purposes ( $7 \mathrm{~d}$ ) and to include sufficient cloud-free days $(30 \mathrm{~d})$. Satellite images were downloaded and prepared for processing with a specially developed empirical NN algorithm. The dates of the images and in situ measurements are given in Table 1. Subsets were created and extracted from the images by selecting Ildır Bay with a minimum $30 \mathrm{~km}$ radius buffer zone. The subset images were processed using the ICOL processor module in the Beam Visat 4.8 software. The Case 2 Regional Processor (C2R) in the Beam Visat 4.8 software was used for the atmospheric correction step. The C2R is a 2-step procedure; in the first step, it uses an NN for atmospheric correction. In the second step, the $\mathrm{C} 2 \mathrm{R}$ algorithm uses an NN water algorithm to estimate water quality variables. Inputs to the first 
Table 1. MERIS image and field study dates which were used for data calibration. Dates are given as dd/mm/yy

\begin{tabular}{|lccccccc} 
MERIS & $19 / 02 / 10$ & $23 / 03 / 10$ & $20 / 04 / 10$ & $14 / 06 / 10$ & $09 / 07 / 10$ & $07 / 09 / 10$ & $11 / 02 / 11$ \\
Field study & $18-19 / 02 / 10$ & $22 / 03 / 10$ & $19-20 / 04 / 10$ & $13-14 / 06 / 10$ & $08-09 / 07 / 10$ & $06-07 / 09 / 10$ & $11-12 / 02 / 11$
\end{tabular}

step NN are the standard top of the atmosphere radiance reflectance, together with the sun and viewing angles (Doerffer \& Schiller 2008). Outputs are the water-leaving reflectance for the same angles. C2R provided these data as output that was used for calibration with field data along with the second step of the $\mathrm{C} 2 \mathrm{R}$ Processor. Field station coordinates were superposed on atmospherically corrected pixels on the images. Adjacent pixels of $3 \times 3$ were exported for every station's matched pixel and averaged to calibrate the data using field observations.

Data from the entire study area were also extracted by creating a mask area using the Rectangle Drawing Tool in Beam Visat. Extracted data were collected in MS Excel as the input to the empirical NN algorithm of the study area.

\section{Data analysis}

\section{Empirical NN algorithm}

In this study, the first 8 bands of water-leaving reflectance obtained after the atmospheric correction step of the $\mathrm{C} 2 \mathrm{R}$ processor were chosen as NN input values; the NN output values were TSM and SDD in 2 different NNs. Clementine 11.1 software (SPSS; user guide available at http://home.kku.ac. th/wichuda/DMining/ClementineUsersGuide_11.1. pdf) was used to build the NN model. The software includes 6 different methods for NN modeling, namely the quick, dynamic, multiple, prune, radial basis function network (RBFN), and exhaustive prune multiple methods. The exhaustive prune multiple method was used to build NNs in this study, because it provided the best results after training multiple times. It creates several networks of different topologies at the same time; it was trained in a pseudo-parallel fashion. At the end of training, the model and topology with the lowest root mean square error (RMSE) was presented as the final model. The software also includes a partition field option to separate the dataset into 2 partitions: 1 for training and 1 for testing. While a subdataset was used to train the neural network model, the other sub-dataset was used to validate the model.
Two different NNs with 1 input and output layer and 2 hidden layers were trained for TSM and SDD. The amount of data and the resolution of satellite images with the size of the study area (number of pixels) make computational time available to set different models with different topologies for each variable. The total TSM and SDD datasets were divided into 2 sub-datasets (partitions) using the Clementine partition module for training and testing. Different partition percentages between 50 and $60 \%$ for the training sub-dataset were set with different training methods and topologies. The best training and testing efforts were chosen for each variable.

The output of the network was compared to the in situ measurements of the variables. The RMSE and the coefficient of determination $\left(\mathrm{R}^{2}\right)$ of the comparison were then calculated to evaluate the performance results of the network.

\section{Validation of the empirical algorithm in shallow} waters

The bottom effect is a widely known problem of shallow water, in which reflection from the bottom can contribute to the water-leaving radiance. To test the contribution of sea bottom reflection to the waterleaving reflectance at different wavelengths, 2 control stations were chosen in the shallow region of the bay, with depths of less than $5 \mathrm{~m}$. These 2 stations were located close to the in situ measurement stations 1 and 2 in Fig. 1. Therefore, it was expected that these 4 stations have similar performances if there is no effect from the sea bottom. Data from control stations were collected during sampling in February 2010 and 2011, March 2010, April 2010, June 2010, and July 2010.

\section{Building the GIS environment and definition of aquaculture impact zones}

The base map layer of the study area was the same as that used by Demirel (2010). Bathymetric layers were created from navigation chart no. 2223 published by the Office of Navigation, Hydrography, and Oceanography, the national authority in Turkey. The image was registered manually to the latitude/longi- 
tude coordinate system in the GIS environment. Depth data were then extracted from a geographically registered navigation chart by on-screen digitizing in the GIS software. The depth data layer was interpolated using the natural neighborhood method to convert the point vector layer to a grid data layer. The first $5 \mathrm{~m}$ of contour layers were used with a base map layer to discard pixels in shallow depths for further analysis in order to eliminate the sea bottom effect of shallow waters. These 2 layers were also used together to visualize the outputs of the algorithm.

Impact zones, i.e. the zones around the vicinity of fish farm cages, were defined and classified for 2 cases and 2 regional groups, which are used for aquaculture in the bay. One is in the central Ildır Bay (Region I) and the other is in the central Gerence region of the bay (Region G; Fig. 1). The borders of the impact zones were determined as $300 \mathrm{~m}$ away from the margins of the cage platforms in the first case (coded I1 in the central Ildirl region and G1 in the Gerence region). In the second case, the impact zones were narrowed to a distance of $1.2 \mathrm{~km}$ (Region I) and $0.6 \mathrm{~km}$ (Region G) inside the borders of both zones of the first case (I2, G2; Fig. 1). Thus, it was possible to evaluate the impact in 2 different regions with 2 different coverages of each region. The pixels within the borders of the defined cases were used to calculate parameters in the impact zone. Each case of both impact zones (I1/G1, I1/G2, etc.) was matched to the others. The remaining pixels of these matches (R1 for I1/G1, R2 for I2/G1, R3 for I1/G2, and R4 for I2/G2) were used for evaluations outside of the impact zones (R). All pixels, which cover the whole bay (A), were used to calculate the average parameter for the entire bay.

\section{Statistical analysis}

Similarity indices (for definition see Johnston 1976) were used on time series data to evaluate similarities and dissimilarities among variable parameters of impact zones (I and $\mathrm{G}$ zones), outside of the impact zones (R zone), and the entire bay (A). Daily parameters are the averaged values of the zones over 1 sampling day. A Euclidian similarity index was used for the dataset of continuous variables, and the results were classified by using cluster analyses and multi-dimensional scaling (MDS, Groenen \& van de Velden 2004).

The obtained data were statistically analyzed by applying ANOVA with 2 groups of equal sample sizes in order to test whether the environment of the bay and/or aquaculture impact zones had any significant differences in terms of TSM and SDD.

\section{RESULTS}

\section{In situ data}

TSM and SDD were measured over 7 mo between February 2010 and February 2011, and a total sample of 73 data points were collected, which were available for matching with data from MERIS FRS images. The largest sample size $(\mathrm{N}=23)$ was collected in February 2011, and the smallest $(\mathrm{N}=4)$ in March 2010 due to cloud coverage pattern in some parts of Ildır Bay. The TSM dataset ranged between 0.12 and $7.0 \mathrm{mg} \mathrm{l}^{-1}$ (mean $\pm \mathrm{SD} 1.44 \pm 1.41 \mathrm{mg} \mathrm{l}^{-1}$ ), and the SDD dataset ranged between 6 and $20 \mathrm{~m}$ (mean \pm SD $11.64 \pm 3.68 \mathrm{~m})$.

\section{Validation and comparison with field observations}

To validate the outputs of MERIS FRS images with the field datasets, data from the C2R algorithms of MERIS were matched to the field data. The TSM concentration output of the $\mathrm{C} 2 \mathrm{R}$ algorithm was chosen for TSM, and Z90_max (maximum signal depth for remotely sensed light) was matched to SDD. Minimal depth at stations used in the data set for validation was $12 \mathrm{~m}$, while minimum SDD was $6 \mathrm{~m}$. Minimal depth was twice the SDD to reduce the bottom effect on radiance. Both datasets showed no significant relationship between the remotely sensed data and the field measurements. Fig. 2 shows the relationship between the TSM and SDD datasets. The results show that the C2R algorithm of MERIS is not valid in Ildır Bay, thus a local algorithm is required for this bay.

A local empirical NN algorithm was set and validated to improve the results. The empirical NN algorithm was designed in 4 layers as input, hidden 1 , hidden 2, and output layers. Eight input nodes and 1 output node were the same for both TSM and SDD, while hidden 1 and hidden 2 layers had 12 and 10 nodes for TSM, and 19 and 17 nodes for SDD, respectively. While the percentages of training and testing datasets were $55 \%$ and $45 \%$ for the SDD samples, they were $52 \%$ and $48 \%$ for the TSM samples, respectively. The estimated accuracy, which is used to represent the number of times the model performed correctly as a percentage, was $97.48 \%$ for TSM and $99.58 \%$ for SDD. Statistical comparisons of neural network training, testing, and total datasets for both parameters are shown in Table 2 and Fig. 3. The results show a significant relationship between the estimated and measured values. Although training 

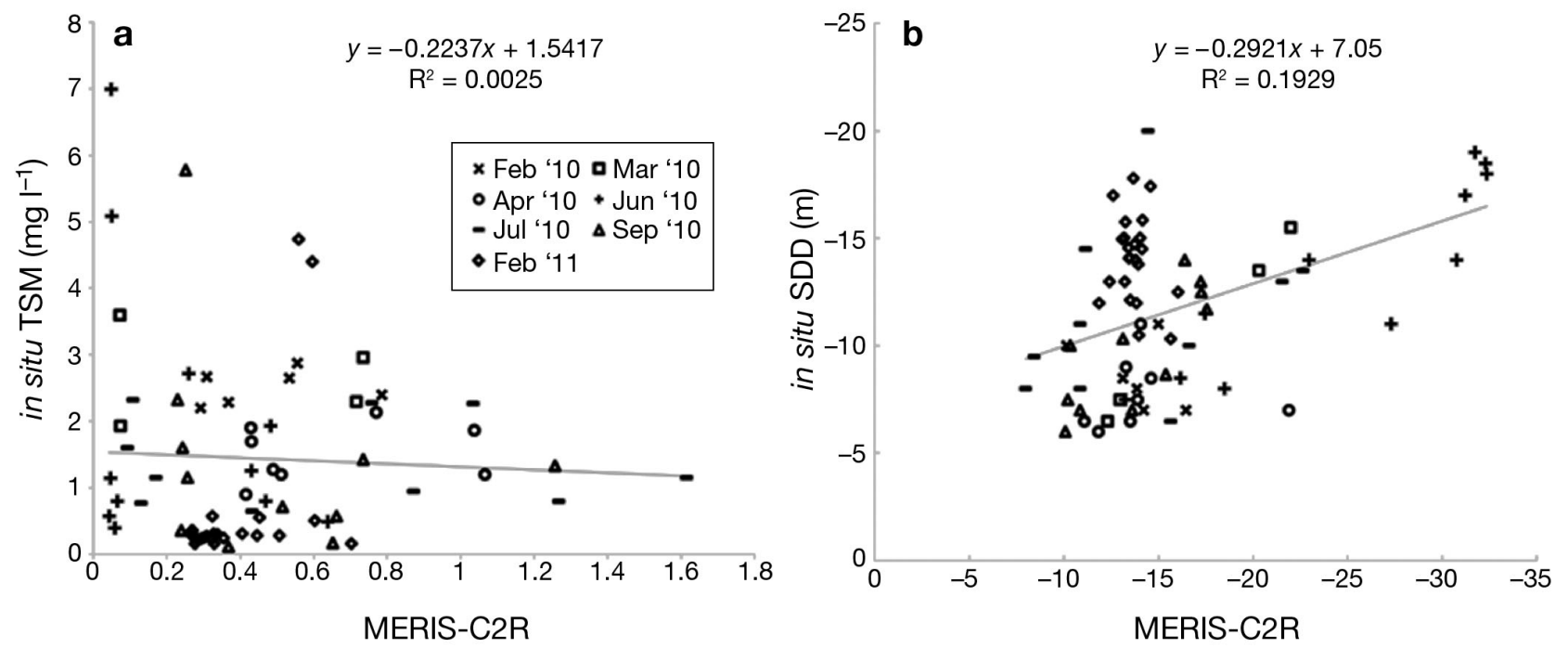

Fig. 2. Relationship between in situ observations and outputs of the MERIS algorithm: (a) total suspended matter (TSM, mg $\mathrm{l}^{-1}$ ) and (b) Secchi disk depth (SDD, m)

sub-datasets have better performance than testing ones, testing sub-datasets also have high $\mathrm{R}^{2}$ values. This implies that the model can produce acceptable outputs with datasets that do not include values from the training dataset. Selected statistical comparisons of the datasets are shown in Table 2.

The result of the algorithm in shallow waters shows that control stations do not demonstrate a good relationship between estimated and measured values $\left(\mathrm{R}^{2}=0.30\right)$, although parallel stations have a significant relationship between field measurements and estimated values $\left(R^{2}=0.99\right)$ and display a similar range. There are also large differences between the ranges of measured and estimated datasets. This indicates that those shallow regions might cause high errors in the estimations, thus the algorithm cannot cope with the data obtained in these regions. Therefore, the model cannot take into account data derived in shallow regions for further analysis because of the significant effect of the sea bottom. This demonstrates the importance of using the 0-5 $\mathrm{m}$ depth region mask in the produced maps.

\section{TSM and SDD distribution in the study area}

Data derived from the empirical NN algorithm for each day, all impact zones, and the entire bay were used to calculate the daily parameter, which is the average value of TSM and SDD in 1 image for a single day. Seasonal parameters for the variables were calculated using the daily parameters. Seasonal parameters were then chosen for visualization because of the variability in the daily fluctuations.

Most impact zones had the lowest TSM concentrations in winter 2011, and only Zones I2 and R2 had their lowest TSM concentrations in autumn 2009. A similar shift was seen in the highest TSM concentrations; Zones G1 and G2 had the highest concentrations in summer 2010, whereas the other zones had the highest concentrations in spring 2010. Regarding SDD, the highest penetration occurred in winter 2010 for Zones G1 and G2, and in autumn 2009 for all other zones. Similarly, the lowest penetrations occurred in summer 2010 in Zones G1 and G2 and in spring 2010 in all other zones. Distributions of sea-

Table 2. Resulting features of the networks and statistical comparison of neural network training, testing, and total dataset

\begin{tabular}{|c|c|c|c|c|c|c|}
\hline \multirow[t]{2}{*}{ Statistics } & \multicolumn{3}{|c|}{ Secchi disk depth } & \multicolumn{3}{|c|}{ Total suspended matter } \\
\hline & Training & Testing & Total & Training & Testing & Total \\
\hline Minimum error & -0.37 & -0.591 & -0.59 & -1.004 & -1.489 & -1.49 \\
\hline Maximum error & 0.414 & 0.359 & 0.414 & 0.539 & 1.109 & 1.109 \\
\hline Mean error & 0.014 & -0.019 & -0.001 & -0.021 & 0.015 & -0.004 \\
\hline Linear correlation (r) & 0.999 & 0.999 & 0.999 & 0.991 & 0.937 & 0.975 \\
\hline $\mathrm{R}^{2}$ & 0.999 & 0.999 & 0.999 & 0.981 & 0.878 & 0.951 \\
\hline Root mean square error & 0.125 & 0.134 & 0.129 & 0.233 & 0.383 & 0.314 \\
\hline $\mathrm{N}$ & 40 & 33 & 73 & 38 & 35 & 73 \\
\hline
\end{tabular}



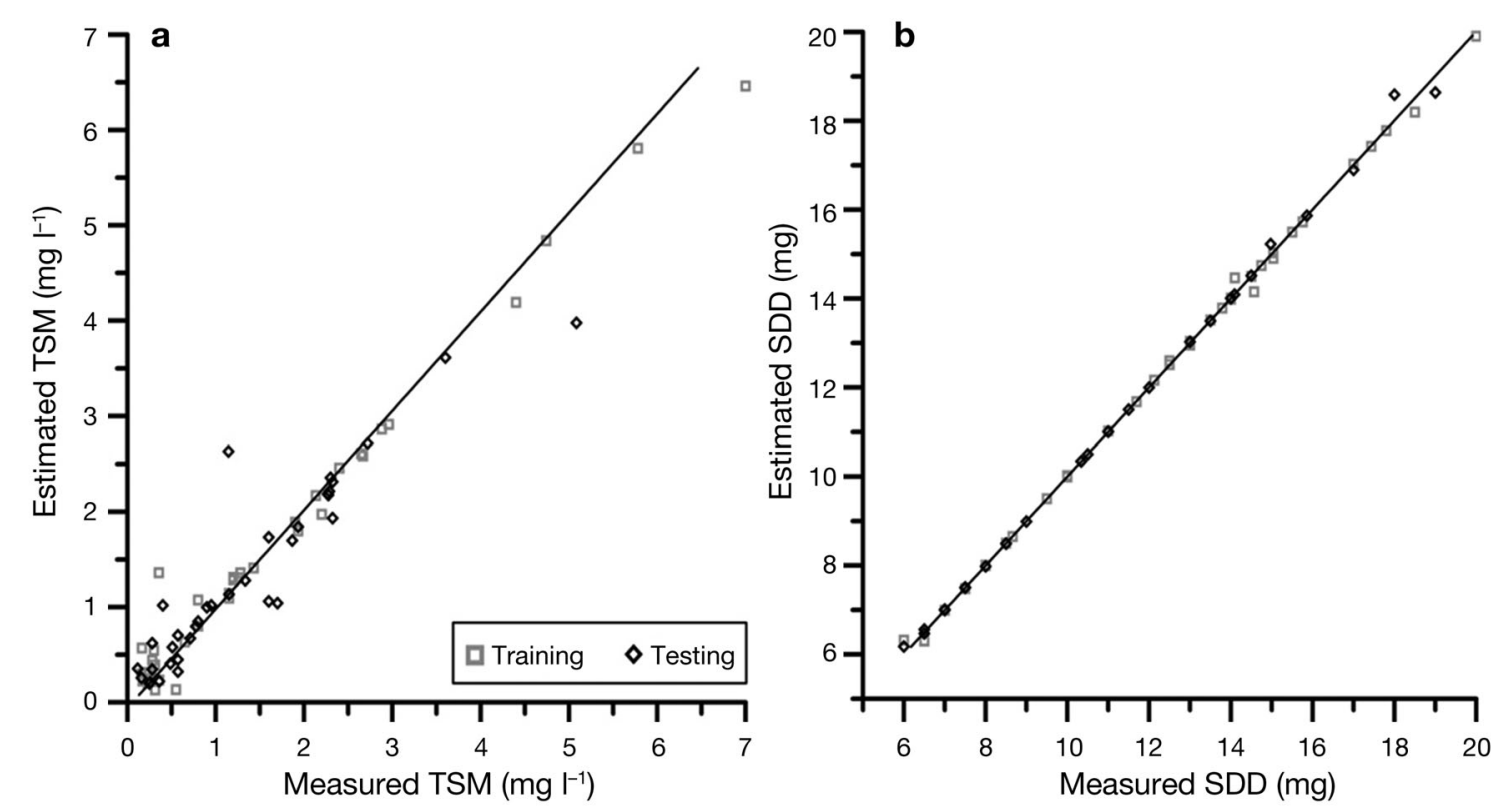

Fig. 3. (a) Total suspended matter (TSM) and (b) Secchi disk depth (SDD) estimated from MERIS versus field measurements. In both cases, 73 data points were used. Training and testing datasets are shown in different symbols. Average estimated and average measured TSM was 1.45 and $1.44 \mathrm{mg} \mathrm{l}^{-1}$, respectively, with a coefficient of determination $\left(\mathrm{R}^{2}\right)$ of 0.951 . Average and measured SDD were both $11.64 \mathrm{~m}\left(\mathrm{R}^{2}=0.999\right)$

sonal averages of TSM and SDD are presented in Figs. 4 \& 5. A 1-way ANOVA to test for seasonal differences in terms of TSM and SDD showed significant differences in Zones G1 and G2. Results of ANOVA for 2 groups with equal sample sizes are presented in Table 3. The ANOVA results show no significant differences between all paired regions. Fig. 6 presents the anomalies for all zones in the entire Ildırı Bay, and shows that the highest positive anomalies occurred in Zones G1 and G2. Zones I1 and I2 also had high anomalies, but mostly in the negative sense. It should be noted that the I and G zones had different temporal patterns.

Similarity analyses were performed to evaluate the zones' similarities in terms of TSM and SDD. Clusters in Fig. 7 show 3 main groups based on the daily TSM and SDD parameter variability in all zones. Similarly, MDS plots in Fig. 7 enable us to evaluate similarity of the location of each group that is distinguished in the cluster groups. The MDS analysis clearly demonstrated, without any transitionary pattern, 3 distinct groups of zones which are composed by the I zones, $\mathrm{G}$ zones, and others, i.e. $\mathrm{R}$ zones and the whole bay (A1 zone).

\section{DISCUSSION AND CONCLUSION}

The highest concentrations of TSM and the lowest penetrations of SDD correspond to the summer and spring seasons (see Fig. 9). The G zones showed a seasonal shift in comparison with the other zones. Similarity analyses also support this seasonal shift. Spring is the period of highest TSM concentration for $\mathrm{R}$ and I zones and the entire bay, which means an increase in TSM concentration occurred throughout the bay. This might be attributed to spring blooms in the bay and adjacent waters. Spring bloom trends were generalized by Cebrian \& Valiela (1999), who pointed out that phytoplankton concentrations peaked in the spring and late summer in areas with a bimodal cycle such as those in enclosed coastal systems. Observations from a meteorology station point out that the year 2010 was one of the most arid years for the region, particularly between March and September, thus precipitation and temporary outflows are not potential particle sources during this period. Wind also has an important effect on water circulation in the Aegean Sea. Even though there is no specific study of water circulation and hydrography in Ildır Bay, the high sensitivity of the Aegean Sea to climatic variability was pointed out by Zervakis et al. (2004). Furthermore, Sayın (2003) mentioned that wind conditions influence the horizontal and vertical stratification in Izmir Bay, a bay adjacent to Ildırı Bay. While westerly and northerly winds force the transport of Aegean Sea surface water, winds from a southerly direction prevent Aegean inflow into Izmir Bay. From the predominant wind patterns, it is clear that during the spring and summer, the wind is pre- 


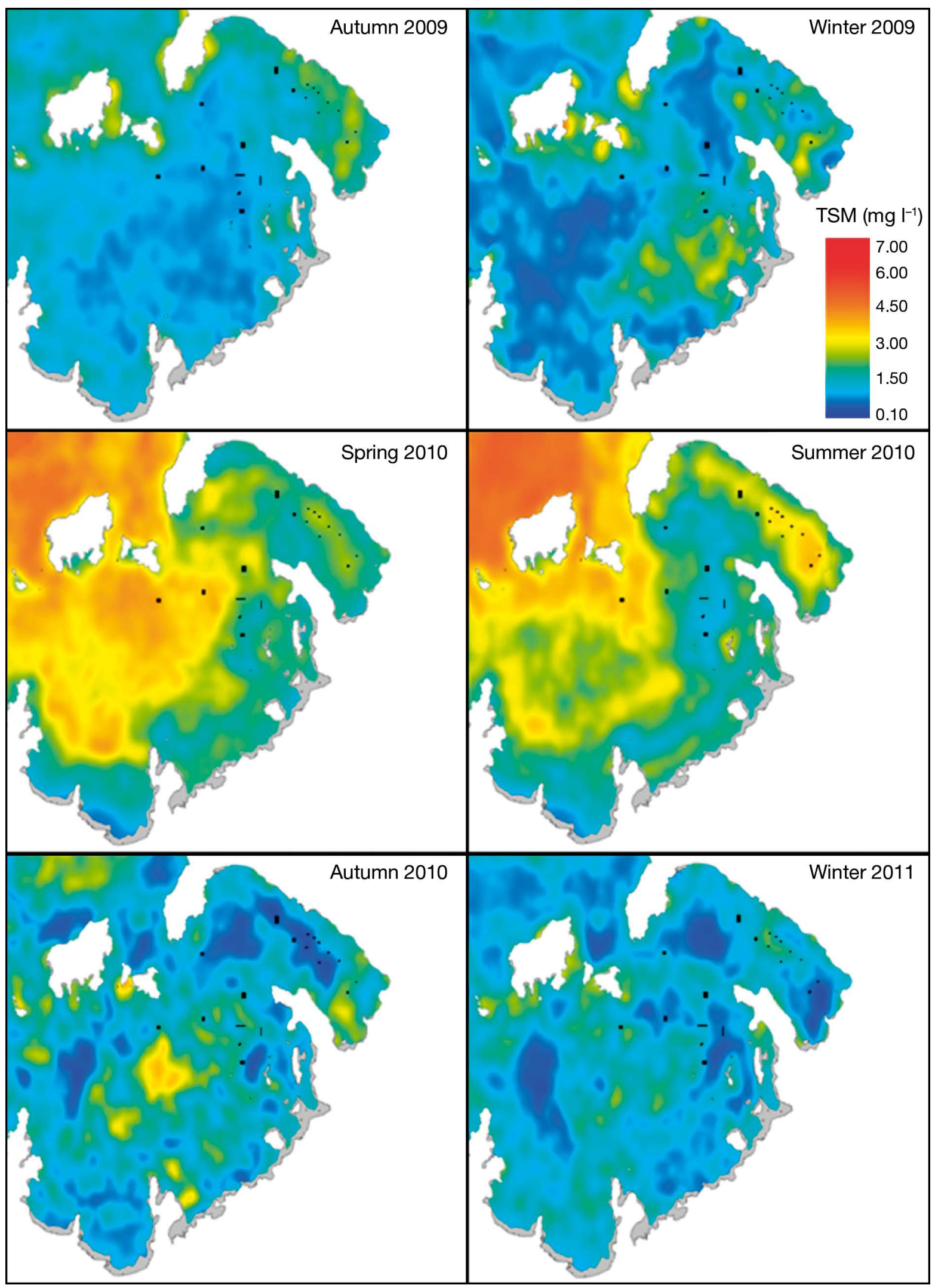

Fig. 4. Seasonal distribution of total suspended matter (TSM; black boxes show aquaculture areas, see Fig. 1) in Ildırı Bay 


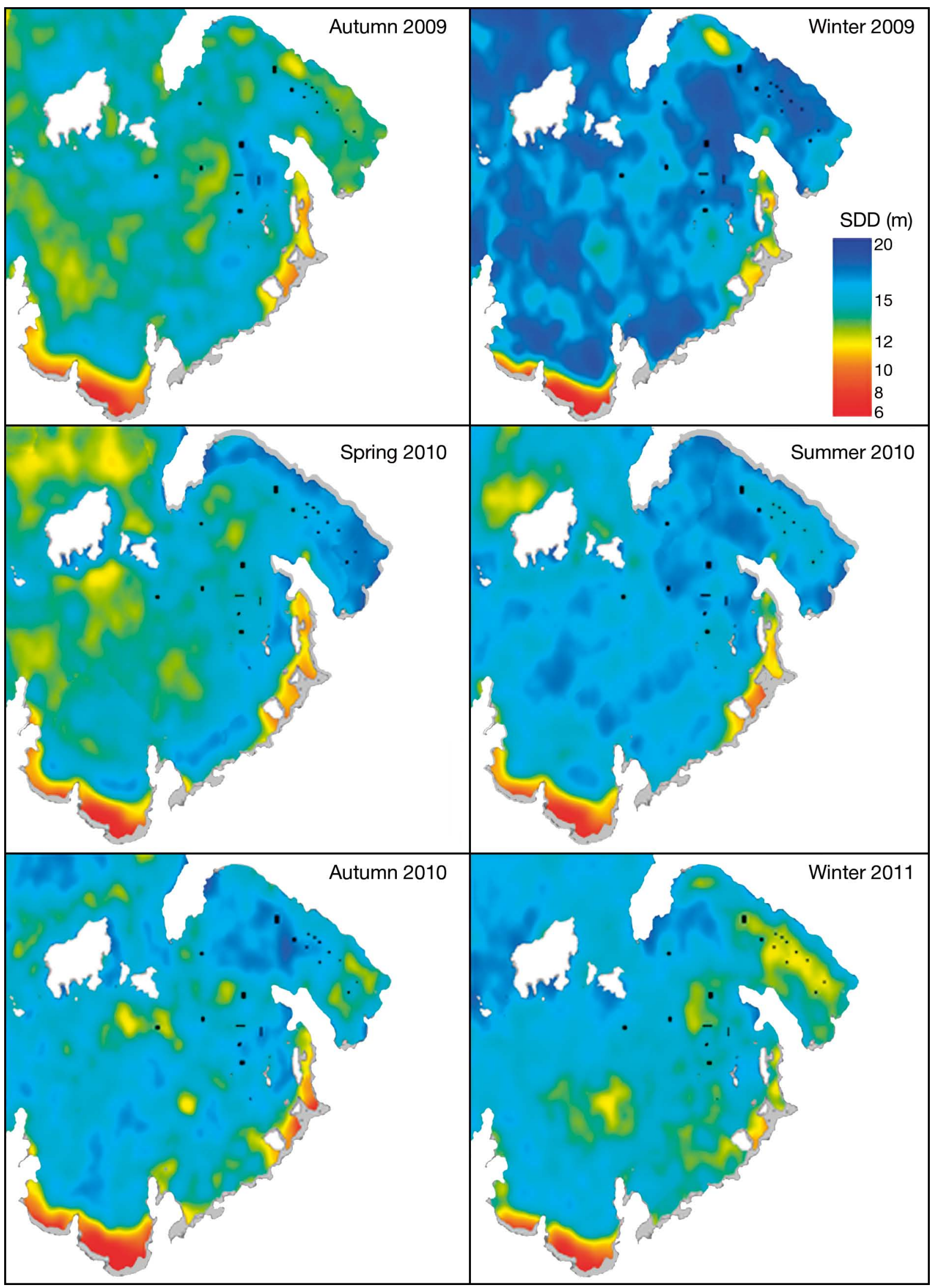

Fig. 5. Seasonal distribution of Secchi disk depths (SDD; black boxes show aquaculture areas, see Fig. 1) in Ildırı Bay 
Table 3. One-way ANOVA analysis of total suspended matter (TSM, below the diagonal) and Secchi disk depth (SDD, above the diagonal) between Ildırı Bay daily averages and aquaculture region daily averages $\left(F_{1,72}=3.974, \alpha=0.05\right)$. Zones (regions) are illustrated in Fig. 1

\begin{tabular}{|cccccccccccc|}
\hline & & G1 & G2 & I1 & I2 & R1 & R2 & R3 & R4 & A1 & \\
\hline & & & & & & & & & & & \\
G1 & - & 0.04 & 0.32 & 0.63 & 0.13 & 0.14 & 0.11 & 0.12 & 0.20 & \\
G2 & 0.04 & - & 0.12 & 0.36 & 0.02 & 0.02 & 0.01 & 0.02 & 0.05 & \\
I1 & 2.42 & 3.12 & - & 0.09 & 0.05 & 0.05 & 0.08 & 0.07 & 0.02 & \\
I2 & 1.37 & 1.86 & 0.06 & - & 0.26 & 0.25 & 0.31 & 0.29 & 0.19 & \\
TSM & R1 & 0.28 & 0.55 & 1.14 & 0.50 & - & 0.00 & 0.00 & 0.00 & 0.01 & SDD \\
R2 & 0.45 & 0.78 & 0.86 & 0.34 & 0.02 & - & 0.00 & 0.00 & 0.01 & \\
R3 & 0.25 & 0.51 & 1.30 & 0.58 & 0.00 & 0.04 & - & 0.00 & 0.02 & \\
R4 & 0.40 & 0.73 & 1.01 & 0.40 & 0.01 & 0.00 & 0.02 & - & 0.01 & \\
A1 & 0.47 & 0.81 & 0.88 & 0.34 & 0.02 & 0.00 & 0.04 & 0.00 & - & \\
\hline
\end{tabular}

dominantly from the north, while during winter and fall, it is predominantly from the south. TSM maps for spring 2010 and summer 2010 show particle loading from outside the bay (the northern part of the Çeşme Strait). Considering these findings, wind direction may be among the major sources of TSM in the surface in this area during the spring and summer. These facts indicate that the spring bloom is a potential particle source for Ildır Bay. The anomaly in the TSM graphics shows a positive trend in the G zones, excluding the summer period. Increasing particle concentration in the entire bay due to spring bloom in the summer could be a reason for the summer time negative anomaly in the G zones. On the other hand, the shift in the highest summer concentration in these zones may be explained by increasing inputs from aquaculture activity. In high temperatures, the rate of metabolic activity of fish increases, which means more feeding, and thus more excreted particles enter the seawater during this season (Fujiya 1979, Wedemeyer 1996). It was also noted that the arid period without any rainfall continued during this season as well.

To understand the influence of wind speed and wind direction on TSM and SDD distributions, MDS, principle component analysis, and ANOSIM were applied. The analyses did not show any significant effect of wind on TSM and SDD distributions. Insufficiency in available data in terms of sample size and high variance were the main restrictions.

Similarity analyses showed that the $\mathrm{G}$ and I zones are not only different from the entire bay and other zones, and but also from each other. Circulation patterns might be the reason for this difference among impact zones. The I zones are located in the central part of Ildır Bay, which is connected to open water by the Chios Strait. Therefore, these zones are under the influence of water from outside the bay, by a more dynamic circulation character. This dynamic circulation could disperse the particles more efficiently and result in lower TSM concentrations and higher SDD penetration. The G zones have relatively enclosed geography and shallower depths compared to the I zones. Limited water exchange with outside the bay, bathymetric differences, and being surrounded by land could reduce the efficiency of circulation patterns in this region, and thus could result in poor particle dispersal. This contrasting difference in water circulation patterns may explain why the 2 impact zones have different characteristics.

However, the absence of the expected negative correlation between TSM and SDD has also been observed in TSM and SDD anomaly trends (Fig. 6), which are only weakly related on a temporal scale.
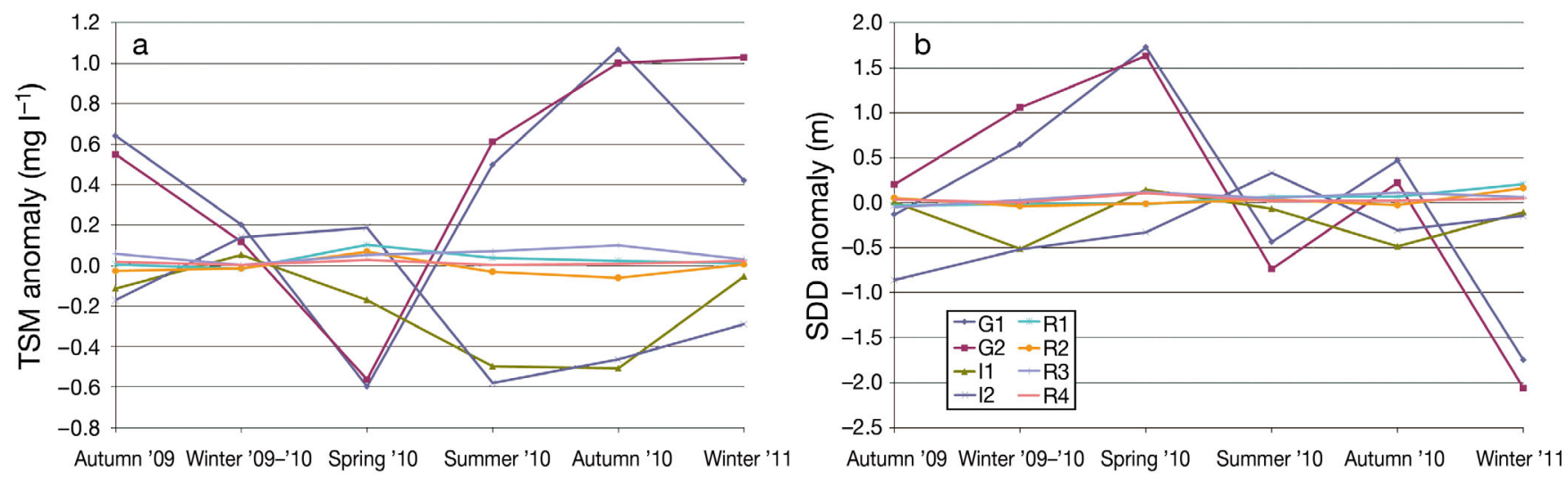

Fig. 6. Seasonal anomalies of (a) total suspended matter (TSM) and (b) Secchi disk depth (SDD) in the impact zones (differences from Zone A1, i.e. the entire bay). See Fig. 1 for impact zone descriptions 


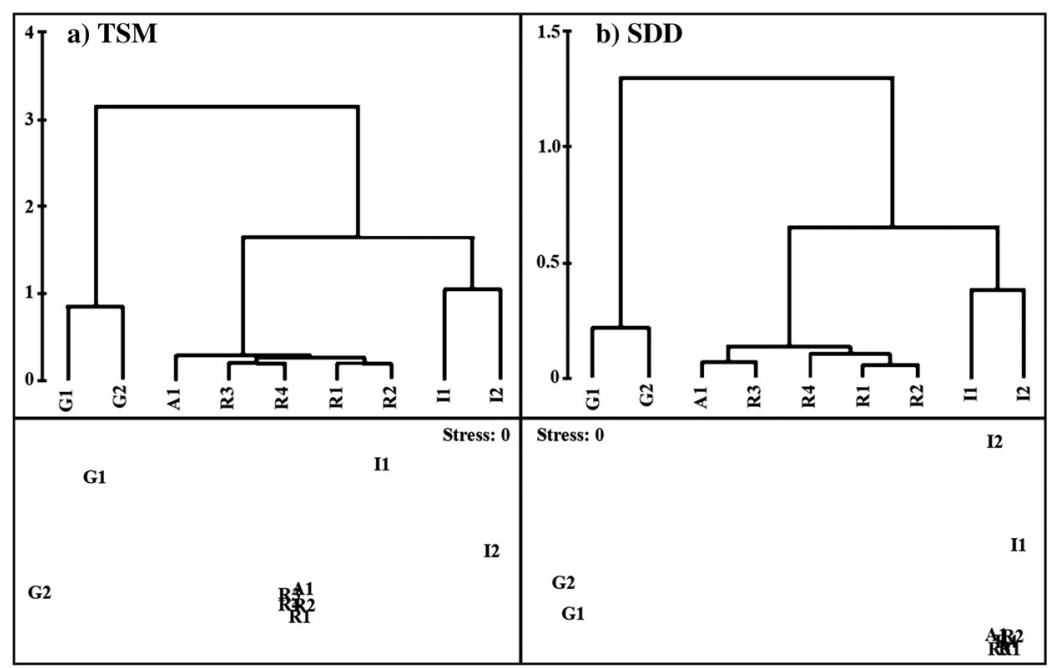

Fig. 7. Cluster and multidimensional scaling (MDS) diagrams of (a) total suspended matter (TSM) and (b) Secchi disk depth (SDD). Clusters show 3 main groups based on daily TSM and SDD parameter variability in all zones of Ildırı Bay. MDS plots enabled us to evaluate the similarity of the location of each group distinguished in the cluster groups. The MDS analysis clearly demonstrated 3 distinct groups of zones: I zones, G zones, and all others, i.e. R zones and the whole bay (A1 zone) (see Fig. 1)

The relationship between TSM and SDD correlation coefficients over individual sampling days supports these differences in the trends of anomalies of the 2 variables (Fig. 8). It is obvious that TSM is not the only main contributor that determines turbidity and thus the penetration SDD, even though for some days it has a high negative correlation with SDD. This provides evidence for interference by another optically active component. The importance of determining which of these optically active components is more effective in determining the underwater light field. Correspondence of low SDD values with low TSM values suggests the importance of colored dissolved organic matter (CDOM) in determining the underwater light field as an optically active component. Data on dissolved organic carbon (DOC) from project '107Y225' (N. Bizsel unpubl.), as mentioned in the 'Materials and methods' were used to illustrate the relationship between DOC and seasonal SDD:TSM ratios (Fig. 9). This ratio was higher in the winter and autumn than in the summer and spring. In contrast, the DOC amount is higher in the spring and summer. This fact supports the suggestion that CDOM can also influence SDD values.

The great potential of remote sensing for aquaculture applications was pointed out by IOCCG (2009). These applications include site selection, warning systems for harmful algal blooms, and ecological and spatial models. While aquaculture site selection in open water has been generally based on the use of medium spatial-resolution sensors, IOCCG (2009) also indicated that the use of multispectral images from high spatial-resolution sensors are common for site selection for near-shore aquaculture. While high-resolution sensors have more advantages for nearshore aquaculture site selection studies, their costs do not currently make them feasible for time series studies that need observations of monthly, seasonal, or annual changes in variables and their characteristic patterns of marine ecosystems in aquaculture areas.

The low cost of medium-resolution sensors allows for more frequent sampling to determine the relevant variable characteristics of marine ecosystems at the cost of detection ability of highly sensitive spatial changes, in aquaculture areas. MERIS FRS is one of the best products among mediumresolution sensors that offer a trade-off between low cost and high resolution and are preferred for monitoring studies, due to their availability to produce longer and affordable time series data, in spite of their relatively low temporal resolutions. Having better spatial resolution for MERIS FRS, which has 9 times more pixels than other medium-resolution sensors such as MODIS Aqua in the same area, made it possible to use impact zones for further analysis. For instance, Zone G1 has only 1 pixel in the resolution of MODIS, whereas it has approximately 17 pixels in MERIS FRS. Nevertheless, the addition of CDOM to TSM and SDD, as a key variable, should not be overlooked for more efficient and reliable spatial analysis, to compensate for the trade-off in resolution.

To add to the scope of this study, another part of the Aegean Sea was evaluated for the usefulness of the new empirical NN algorithm, based on the TSM range. Table 4 shows the maximum and minimum values from various bays in the Aegean Sea (Karageorgis \& Anagnostou 2001, İnanan 2007, this study). Many of these bays, excluding Izmir Bay, have narrower ranges than those observed in our study, indicating that our algorithm can be applied to other bays of the Aegean Sea, although differences in water composition, such as particle type and size spectrum, and/or proportional differences between TSM and CDOM in these bays are potential sources of possible limitations. 


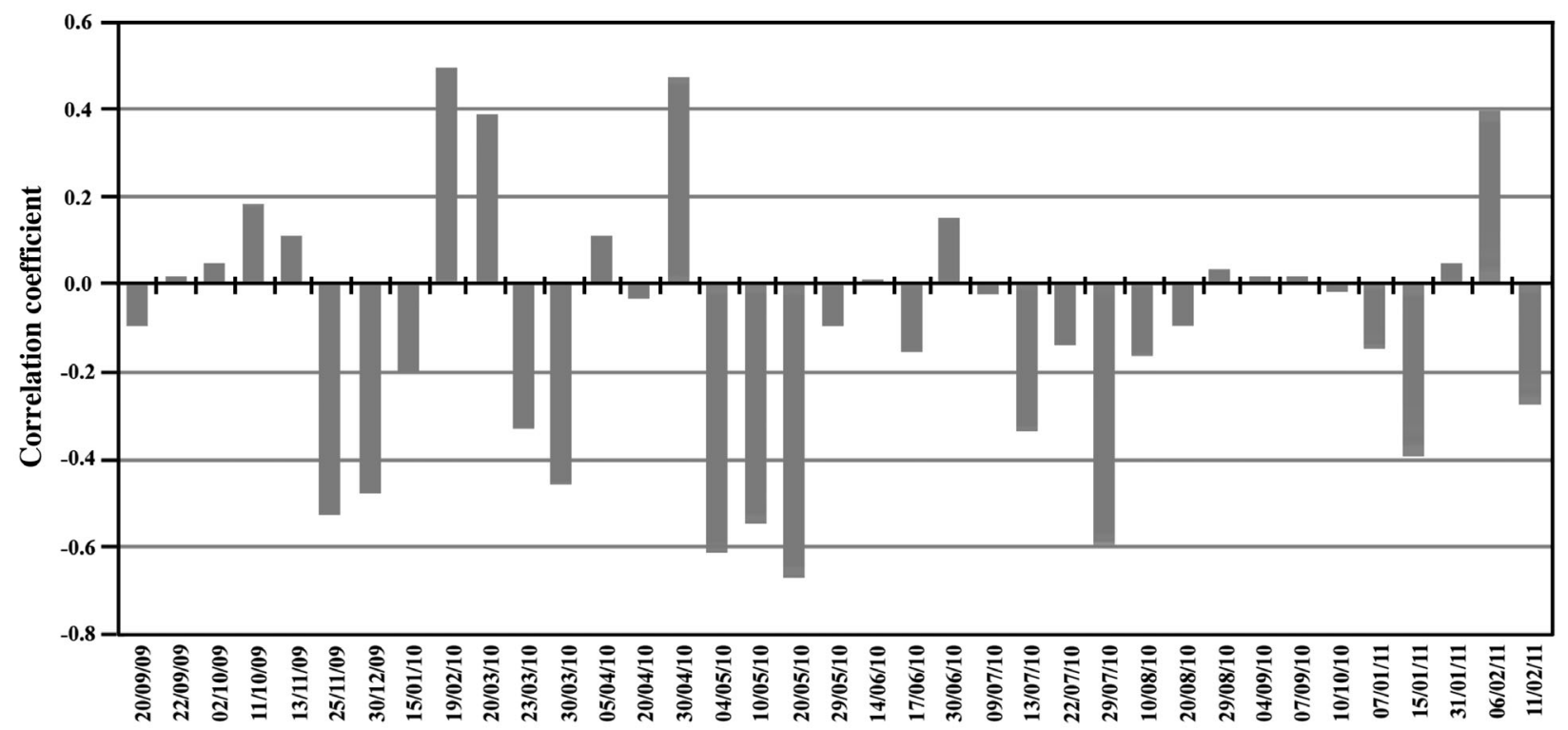

Fig. 8. Correlation coefficients of total suspended matter (TSM) versus Secchi disk depth (SDD) of the entire bay on individual sampling days

Our study could provide important input for modeling studies, designing further studies, or complementing field studies to increase understanding of ecosystem dynamics. For instance, our results made clear that the summer and part of the spring are key seasons when aquaculture activity is highly likely to impact the environment, depending on the prevailing dynamics of the circulation system and phytoplankton of the bay. On the other hand, an information system that includes data on aquaculture activities in Turkey would help to increase the benefit of such analyses based on the remotely sensed data. According to a directive published in the Official Gazette of the Republic of Turkey in 2007 (see www.resmigazete.gov.

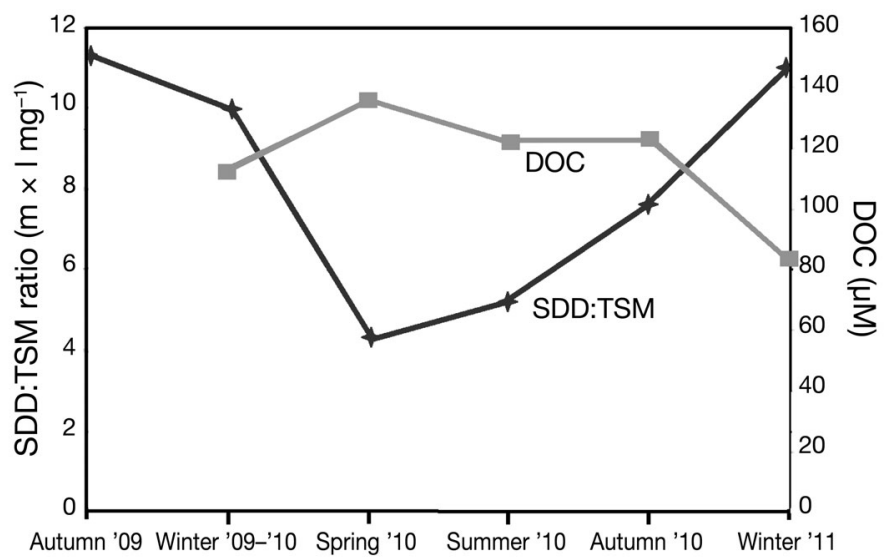

Fig. 9. Seasonal Secchi disk depth:total suspended matter (SDD:TSM) ratios (left axis) and dissolved organic carbon (DOC) distributions (right axis; N. Bizsel unpubl. data) of the entire bay tr/main.aspx?home=http://www.resmigazete.gov.tr/ eskiler/2007/01/20070124.htm\&main=http://www. resmigazete.gov.tr/eskiler/2007/01/20070124.htm), existing or planned aquaculture facilities must comply with a suite of requirements for site selection. A large-scale relocation plan for these facilities was implemented in the last quarter of 2009 in Ildır Bay in accordance with the directive. Currently, without field observations and measurements, it is not possible to determine whether the cages have been moved or not. Such movements, as well as the alterations in their environmental impacts, could be easily monitored and assessed by exploiting remote sensing technology. This fact clearly displays the importance of an extensive information system that includes remote sensing applications for monitoring not only aquaculture but also other activities that have been causing pressures on coastal marine environments.

Table 4. Maximum and minimum total suspended matter (TSM) concentrations from bays of the Aegean Sea

\begin{tabular}{|c|c|c|}
\hline Area & Max & Min \\
\hline Thermailos Gulf and Sporades Basin ${ }^{\mathrm{a}}$ & 4.97 & 0.03 \\
\hline Northern Aegean Sea ${ }^{\mathrm{a}}$ & 6.19 & 0.05 \\
\hline Pagassitikos Gulf ${ }^{\mathrm{a}}$ & 1.53 & 0.04 \\
\hline Saronikos Gulf ${ }^{\mathrm{a}}$ & 1.84 & 0.09 \\
\hline Izmir Bay ${ }^{b}$ & 13.25 & 0.60 \\
\hline Ildırı Bay ${ }^{\mathrm{c}}$ & 6.92 & 0.12 \\
\hline
\end{tabular}

${ }^{\mathrm{a}}$ Karageorgis \& Anagnostou (2001); ${ }^{\mathrm{b}}$ Inanan (2007); 'This study 
Acknowledgements. This study was conducted as an integral part of a research project (107Y225) carried out in 2008-2011, which was supported by TUBITAK (The Scientific and Technological Research Council of Turkey). This study was also inspired, motivated, and supported by the EC 7th FP Project: DEVOTES (full title: Development Of innovative Tools for understanding marine biodiversity and assessing good Environmental Status) Grant agreement no: 308392 and published as a contribution to the project efforts. This article is a product of a Master of Sciences Thesis entitled 'Determination of the Impacts of Marine Farms on Marine Ecosystems by Using Remote Sensing: Ildır Bay' in the Graduate School of Natural and Applied Sciences at Dokuz Eylül University. We thank the project team for their help in fieldwork.

\section{LITERATURE CITED}

Akyurt H (2008) Turizm Bölgesine Yönelik Talebi Etkileyen Faktörlerden maj ve Çeşme Örneği (Image as a factor influencing demand towards a tourist destination: the case of Çeşme). PhD thesis, Dokuz Eylül University, Izmir

BSGM (General Directorate of Fisheries and Aquaculture) (2013) Su ürünleri statistikleri. Report of the Department of Fisheries and Aquaculture in the Ministry of Agriculture and Rural Affairs. Available at www. tarim.gov.tr/sgb/Belgeler/SagMenuVeriler/BSGM.pdf (accessed 7 January 2014)

Buitrago J, Rada M, Hernández H, Buitrago E (2005) A single-use site selection technique using GIS, for aquaculture planning: choosing locations for mangrove oyster raft culture in Margarita Island, Venezuela. Environ Manag 35:544-556

Bukata R, Jerome J, Kondratyev K, Pozdnyakov D (1991) Satellite monitoring of optically-active components of inland waters: an essential input to regional climate change impact studies. J Gt Lakes Res 17:470-478

Cebrian J, Valiela I (1999) Seasonal patterns in phytoplankton biomass in coastal ecosystems. J Plankton Res 21:429-444

Demirel Y (2010) Kıyı Bölgesinde Yürütülen Faaliyetlerin Deniz Ekolojine Etkileri (Impact of activities in a coastal zone on the marine ecology). MSc thesis, Dokuz Eylül University, Izmir

Doerffer R, Schiller H (2008) MERIS regional coastal and lake Case 2 Water Project atmospheric correction ATBD (Algorithm Theoretical Basis Document) 1.0. GKSS Forschungszentrum, Geesthacht. Available at www.brockmann-consult.de (accessed 26 May 2010)

Fujiya M (1979) Coastal culture of yellowtail (Seriola quinqueradiata) and red sea bream (Pagrus major) in Japan. In: Pillay TVR, Dill WA (eds) Advances in aquaculture. Fishing News Books, Farnham, p 453-358

Giap DH, Yi Y, Cuong NX, Luu LT, Diana JS, Lin CK (2003) Application of GIS and remote sensing for assessing watershed ponds for aquaculture development in Thai Nguyen, Vietnam. Oregon State University, Corvallis, OR. Available at http://pdacrsp.oregonstate.edu/pubs/workplns/wp_10/10GISR2.html (accessed 12 June 2010)

Green EP, Mumby PJ, Edwards AJ, Clark CD (2000) Remote sensing handbook for tropical coastal management. In: Edwards AJ (ed) Coastal management sourcebooks 3. UNESCO, Paris. Available at www.unesco.org/csi/pub/ source/rs.htm (accessed 3 January 2010)

Groenen PJF, van de Velden M (2004) Multidimensional scaling. Econometric Institute Report, EI 2004-15, Erasmus University Rotterdam. Available at http://repub.eur. nl/pub/1274/ei200415.pdf
Inanan EB (2007) Izmir körfezi fitoplankton kompozisyonu ve kompozisyonu etkileyen parametreler (Phytoplankton composition in Izmir Bay and parameters affecting the composition). MSc thesis, Dokuz Eylül University, Izmir

IOCCG (International Ocean-Colour Coordinating Group) (2000) Remote sensing of ocean colour in coastal, and other optically-complex, waters. Reports of the International Ocean-Colour Coordinating Group, No. 3. IOCCG, Dartmouth, NS

IOCCG (2008) Why ocean colour? The societal benefits of ocean-colour technology. Reports of the International Ocean-Colour Coordinating Group, No. 7. IOCCG, Dartmouth, NS

IOCCG (2009) Remote sensing in fisheries and aquaculture. Reports of the International Ocean-Colour Coordinating Group, No. 8. IOCCG, Dartmouth, NS

Johnston JW (1976) Similarity indices I: What do they measure? Battelle Northwest Labs. PNWL-LIS2 NRC-1. Pacific Northwest National Laboratory, Richland, WA

Kapetsky JML, Aguilar-Manjarrez J (2007) Geographic information systems, remote sensing and mapping for the development and management of marine aquaculture. FAO Fish Tech Pap 458. Aquaculture Management and Conservation Service, FAO Fisheries and Aquaculture Department, Rome. Available at www.fao.org/ docrep/009/a0906e/a0906e00.HTM (accessed 21 May 2011)

Kapetsky JML, McGregor H, Nanne E (1987) A geographical information system to plan for aquaculture: a FAOUNEPIGRID study in Costa Rica. FAO Fish Tech Pap 287. FAO, Rome. Available at www.archive.org/stream/geo graphicalinfo034640mbp\#page/n1/mode/2up (accessed 13 May 2010)

Karageorgis AP, Anagnostou C (2001) Particulate matter spatial-temporal distribution and associated surface sediment properties: Thermaikos Gulf and Sporades Basin, NW Aegean Sea. Cont Shelf Res 21:2141-2153

Keiner LE (1999) Neural networks as non-linear function approximation for remote sensing applications. In: Chen $\mathrm{CH}$ (ed) Information processing for remote sensing. World Scientific Publishing Co., Singapore, p 213-223

Keiner LE, Yan XH (1998) A neural network model for estimating sea surface chlorophyll and sediments from thematic mapper imagery. Remote Sens Environ 66:153-165

Pure Salmon Group (2006) Scientist statement on the aquaculture industry's impact on marine ecology and human health. Available at www.puresalmon.org/pdfs/scientist_letter.pdf (accessed 2 May 2011)

Sarà G (2007) Aquaculture effects on some physical and chemical properties of the water column: a meta-analysis. Chem Ecol 23:251-262

> Sayın E (2003) Physical features of the Izmir Bay. Cont Shelf Res 23:957-970

Sipelgas L, Ossipova V, Raudsepp U, Lindfors A (2009) A bio-optical model for the calculation of suspended matter concentration from MODIS data in the Pakri Bay, the Gulf of Finland. Boreal Environ Res 14:415-426

Wedemeyer G (1996) Physiology of fish in intensive culture systems. Chapman \& Hall, New York, NY

Zervakis V, Georgopoulos D, Karageorgis AP, Theocharis A (2004) On the response of the Aegean Sea to climatic variability: a review. Int J Climatol 24:1845-1858

> Zhang Y, Pulliainen J, Koponen S, Hallikainen M (2002) Application of an empirical neural network to surface water quality estimation in the Gulf of Finland using combined optical data and microwave data. Remote Sens Environ 81:327-336 